\title{
Genotypes and phylogenetic relationships of Salmonella typhimurium are defined by molecular fingerprinting of IS200 and $16 \mathrm{~S}$ rrn loci
}

\author{
John Stanley, ${ }^{1 *}$ Namoos Baquar ${ }^{1}$ and E. John Threlfall ${ }^{2}$ \\ ${ }^{1}$ NCTC Molecular Genetics Unit, and ${ }^{2}$ Laboratory of Enteric Pathogens, Central Public Health Laboratory, \\ 61 Colindale Avenue, London NW9 5HT, UK
}

(Received 20 November 1992; revised 25 January 1993; accepted 1 February 1993)

\begin{abstract}
Molecular fingerprints of chromosomal genotypes in Salmonella typhimurium were generated by analysis of variation at the 16S rrn gene loci and the sites of the insertion sequence IS200. Genetic and reference strains of $S$. typhimurium were compared with clinical phage type strains from cases of human salmonellosis. Three $16 \mathrm{~S} \mathrm{rrn}$ profiles, one of which was predominant, were found. The copy number of the Salmonella-specific insertion sequence IS200 varied from 6 to 12, and all insertions were chromosomal. Three of the insertion sites shared by all strains were serovar-specific for $S$. typhimurium. Thirteen distinct profiles of IS200 were detected, providing a high level of intraserovar strain discrimination. Profiles were generally more conserved among genetic and reference strains; representatives of clinical phage type strains, which are recent human isolates, showed much greater diversity of IS200 profiles. Irrespective of their origin, strains could be assigned to IS200 profile groups, phylogenetically related lines identified by combinations of conserved insertion sites. Hybridization profiles of this mobile element are markers of intermediate and short-term evolution in $S$. typhimurium. They provide a fingerprinting scheme for the purposes of genetics, and delineate a molecular typing scheme for the purposes of epidemiology.
\end{abstract}

\section{Introduction}

Bacteria of the genus Salmonella are classified by DNA hybridization and numerical phenotypic taxonomy into seven subspecies (Le Minor, 1988). By serotyping the somatic and flagellar antigen profiles, over 2000 serovars can be distinguished, of which about 40 are isolated in significant numbers as human pathogens in any one year (Threlfall \& Frost, 1990). A particularly common serovar causing salmonellosis in humans is $S$. typhimurium, a globally distributed zoonotic serovar which is common in both cattle and poultry.

Certain strains of $S$. typhimurium have historically also been the subject of intensive genetic analysis. These are descended from original phage types as defined by Lilleengen (1948). Lilleengen type (LT) strains were used by Zinder \& Lederberg (1952) and by Demerec et al. (1955) in classical studies of genetic exchange. The majority of mutants currently used for genetic analysis of the $S$. typhimurium chromosome are derivatives of strain LT2 (Sanderson \& Stocker, 1987). In LT2, Lam \& Roth

\footnotetext{
*Author for correspondence. Tel. 081200 4400; fax 0812007874.
}

Abbreviations: IP, insertion profile; RFLP, restriction fragment length polymorphism. (1983a) identified a small DNA insertion sequence, IS200, which they demonstrated was specific to the genus Salmonella. Six insertion sites of IS200 were mapped around the LT2 chromosome in relation to a set of random insertions of Tn10 (Lam \& Roth, 1983b). The $708 \mathrm{bp}$ nucleotide sequence of the element has been described, and it constitutes the smallest known bacterial insertion sequence (Lam \& Roth, 1986; Galas \& Chandler, 1989). It was subsequently suggested that IS200 is present in Shigella (Gibert et al., 1990) but further investigation traced this to small regions of homology with two Shigella insertion sequences (Gibert et al., 1991) and IS200 may still be considered specific to Salmonella. Studies of the copy number and location of IS200 (the 'IS200 profile') have been made for certain Salmonella serovars of public health significance. These IS200 profiles were well conserved, and had both phylogenetic and epidemiological significance in $S$. enteritidis, S. berta and S. heidelberg (Stanley et al., 1991, $1992 a, b, c)$.

The established subtyping method for epidemiological investigations of human and animal salmonellosis outbreaks is phage typing, which discriminates phenotypically at the intraserovar level (Threlfall \& Frost, 1990). The $S$. typhimurium typing scheme of Callow (1959) has now been extended and more than 200 
'definitive phage types', DTs, have been identified (Anderson et al., 1977a). In 1990 and 1991 the most common phage type amongst strains of $S$. typhimurium isolated from humans in England and Wales was DT 193, whilst other phage types of major epidemiological importance were DTs 49, 104, 208, 12, 108 and 170 (Laboratory of Enteric Pathogens, unpublished results). Further differentiation within phage types has been achieved by plasmid characterization (Willshaw et al., 1980) or plasmid profiling (Threlfall et al., 1990). However, genotypic relationships between strains of these phage types have never been analysed. Similarly, the evolutionary relationships between genetic strains of $S$. typhimurium and naturally occurring pathogenic isolates of the serovar remain unknown. The comparative analysis of molecular markers of genotype for both groups would offer significant new information.

Certain phage types of $S$. typhimurium are important hosts for plasmids encoding multiple drug resistance. If such strains infect humans, the clinical usefulness of therapeutic antibiotics may be compromised (Threlfall et al., 1992). Molecular fingerprinting of the S. typhimurium chromosome may also provide precise background information against which to define the evolution, lateral transfer and dissemination of antibiotic-resistance plasmids.

We have investigated the copy number and location of IS200 in genetic/reference strains and human clinical isolates of the most common phage types of $S$. typhimurium, and compared this information with data for restriction fragment length polymorphism (RFLP) around the 16S rRNA gene ( $r r n)$ loci. There are three aspects which emerge from this study. Firstly, a molecular fingerprint of the chromosomal genotype is provided for strains of $S$. typhimurium. Secondly, evidence is provided that the transposable IS200 element provides a time-branching index of short-term evolution in this serovar. Thirdly, the outline of a molecular typing system for clinical isolates is provided. These three aspects offer novel insights into the molecular genetics, phylogenetics and epidemiology of $S$. typhimurium.

\section{Methods}

Bacterial strains and culture conditions. Strains of S. typhimurium used in this study were from the culture collections of the National Collection of Type Cultures and the Laboratory of Enteric Pathogens and are listed in Table 1. S. typhimurium LT2 was used as a control in the hybridization studies. Stock cultures were maintained on Dorsetegg agar slopes at $20^{\circ} \mathrm{C}$. Strains were grown in nutrient broth for DNA isolation, and purity was checked on blood agar plates.

DNA techniques. Plasmid DNA of S. typhimurium was analysed by the method of Kado \& Liu (1981). Plasmid pIZ45 was purified according to standard methods (Sambrook et al., 1989). A $300 \mathrm{bp}$ probe fragment internal to IS200 was amplified from the $620 \mathrm{bp} P v u I$ fragment of pIZ45 by the polymerase chain reaction (PCR) employing forward and reverse sequencing primers. A probe for restriction site variation in and around the $16 \mathrm{~S} r r n$ genes was generated by PCR employing as primers the sequences 5'GCAACGCGAAGAACCTTACC $3^{\prime}$ and 5'GGTTACCTTGTTACGACTT3', nucleotides 966-985 and 1492-1510 of the Escherichia coli rrnB gene (Brosius et al., 1978). A PCR product of approximately $550 \mathrm{bp}$ was generated from $S$. typhimurium LT2 by standard methods (Innis et al., 1990) and verified on a Nusieve agarose gel (FMC Bioproducts, Flowgen Instruments). PCR products were separated from primers by centrifugal ultrafiltration (Millipore Ultrafree-MC; 30000 NMWL unit) and labelled with 16-dUTP-biotin by random priming (Boehringer-Mannheim kit).

Genomic DNA was extracted from $S$. typhimurium by the method of Wilson (1987), and $5 \mu \mathrm{g}$ quantities were digested with PstI, PvuII, HincII or BgIII. Among these enzymes, which lack restriction sites within IS200, PstI provided the most characteristic profiles and clearest resolution of IS200 bands. Genomic restriction digests or whole plasmid DNAs were electrophoresed in $0.7 \%$ agarose, and vacuumblotted (LKB Vacu-gene apparatus) onto Hybond N nylon membranes (Amersham). Hybridization was performed by standard methods (Sambrook et al., 1989). Hybridized filters were washed twice with each of the following: $2 \times \mathrm{SSC} / 0.1 \% \mathrm{SDS}$ for $5 \mathrm{~min}$ at $20^{\circ} \mathrm{C}$, $0.2 \times \mathrm{SSC} / 0.1 \% \mathrm{SDS}$ for $5 \mathrm{~min}$ at $20^{\circ} \mathrm{C}$ and $0.16 \times \mathrm{SSC} / 0.1 \% \mathrm{SDS}$ for $15 \mathrm{~min}$ at $60^{\circ} \mathrm{C}$. Hybridization reactions were visualized colorimetrically with the BluGENE reagent (Gibco-BRL). Copy numbers of IS200 were deduced from comparison of reproducible hybridization profiles for three enzymes.

Table 1. S. typhimurium strains

\begin{tabular}{|c|c|}
\hline Strain number & Year of isolation, source, epidemiology \\
\hline \multicolumn{2}{|c|}{ Genetic/reference strains } \\
\hline NCTC 50185 & LT2-SL329, trp \\
\hline NCTC 3048 & 1923, Lister Institute \\
\hline NCTC 5710 & 1939, Denmark, F. Kauffmann \\
\hline NCTC 5714 & 1939, Denmark, F. Kauffmann \\
\hline NCTC 8392 & pre-1934, for prep. of $\mathrm{BVi}$ antiserum \\
\hline NCTC 12416 & $\begin{array}{l}\text { LT2, Demerec, } 1960=\text { CIP } 60.62 \text {, type } \\
\text { strain }\end{array}$ \\
\hline NCTC 12116 & $\begin{array}{l}\text { 1983, TA100, for Ames genetic } \\
\text { toxicology testing }\end{array}$ \\
\hline NCTC 12117 & $\begin{array}{l}\text { 1983, TA1535, for Ames genetic } \\
\text { toxicology testing }\end{array}$ \\
\hline NCTC 5715 & 1939, Denmark, F. Kauffmann \\
\hline NCTC 73 & 1917, var. Binns. France, $12: \mathrm{i}: 1,2$ \\
\hline NCTC 9324 & 1949, rough derivative of NCTC 73 \\
\hline NCTC 8298 & 1950 , SW 580, Stocker, non-motile \\
\hline NCTC 5711 & $\begin{array}{l}\text { 1939, Denmark, F. Kauffmann, } \\
1,4,5,12: 1: 1,2\end{array}$ \\
\hline NCTC 10413 & $\begin{array}{l}\text { 1965, for prep. of } \mathrm{H} \text { suspension for } \\
\text { Widal tests }\end{array}$ \\
\hline NCTC 74 & $\begin{array}{l}\text { 1911, ATCC } 13311 ; \text { type strain, } \\
4,5,12: \mathrm{i}: 1,2\end{array}$ \\
\hline NCTC 12023 & 1987, ATCC 14028 , bovine septicaemia \\
\hline
\end{tabular}

Clinical phage type strains P199593 (DT 195) P100836 (DT 49) P226829 (DT 12) P196865 (DT 104) P194376 (DT 193) P188691 (DT 170) P194831 (DT 204) P220187 (DT 108) P213623 (DT 208)

1990, human, sporadic 1987, human, sporadic 1990 , human, sporadic 1990 , human, sporadic 1990 , human, sporadic 1989 , human, sporadic 1990 , human, sporadic 1990 , human, sporadic 1990 , human, outbreak 


\section{Results}

\section{$16 S$ rrn gene profiles}

The optimal resolution of bands was obtained in genomic Southern blots made with PvuII, which lacks restriction sites within the $16 \mathrm{~S} r r n$ gene. The three RFLPs found amongst all strains examined are shown in Fig. 1. The most common $16 \mathrm{~S} r r n$ gene profile was designated Stm-RI and consisted of six bands (Fig. 1, track 3). It was shared by all of the naturally occurring phage type isolates and 13 out of the 16 genetic/reference strains. The second most common profile, designated Stm-RII (Fig. 1, track 2) consisted of five bands, and was shared by NCTC strains 73 and 9324 . NCTC 5715 had a unique six-band profile (Fig. 1, track 1). Four PvuII bands (8,

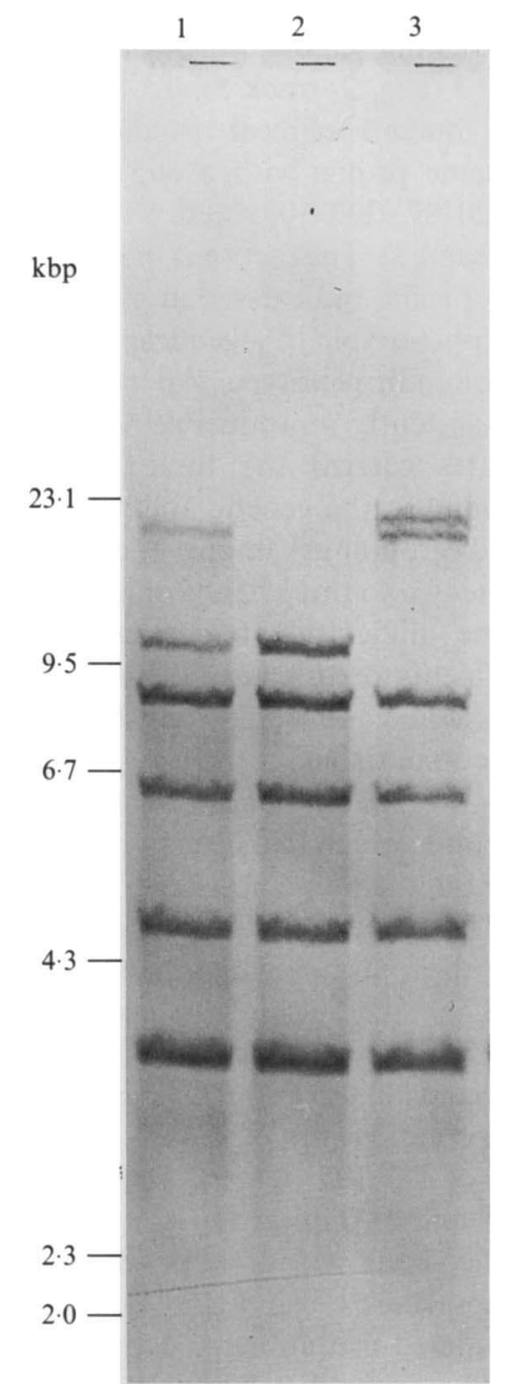

Fig. 1. 16S rrn gene profiles of S. typhimurium. Genomic Southern blot made with PvuII, hybridized with a PCR-generated $550 \mathrm{bp}$ probe internal to the $16 \mathrm{~S} r r n$ gene sequence. Track 1, NCTC 5715; track 2, NCTC 73; track 3, NCTC 50185. These profiles were respectively termed Stm-RIII, Stm-RII and Stm-RI; cf. Table 2.
Table 2. $16 S$ rrn profiles, IS200 copy numbers and plasmid content of the S. typhimurium strains

\begin{tabular}{|c|c|c|c|}
\hline $\begin{array}{l}\text { Strain } \\
\text { number }\end{array}$ & $\begin{array}{l}16 S \mathrm{rrn} \\
\text { profile }\end{array}$ & $\begin{array}{l}\text { IS } 200 \text { copy } \\
\text { number (IP } \\
\text { group) }\end{array}$ & $\begin{array}{l}\text { Plasmid } \\
\text { content } \\
\text { (MDa) }\end{array}$ \\
\hline NCTC 50185 & Stm-RI & $8($ IP1-0) & 60 \\
\hline NCTC 3048 & Stm-RI & $6($ IP1.0) & 60 \\
\hline NCTC 5710 & Stm-RI & $6($ IP1.0) & 60 \\
\hline NCTC 5714 & Stm-RI & $6(\mathrm{IPl} \cdot 0)$ & 60 \\
\hline NCTC 8392 & Stm-RI & $6($ IP1.0) & 60 \\
\hline NCTC 12416 & $S t m-\mathrm{RI}$ & $6(\mathrm{IP} 1 \cdot 0)$ & 60 \\
\hline NCTC 12116 & $S t m-\mathrm{RI}$ & $6($ IP1.0) & 60,20 \\
\hline NCTC 12117 & Stm-RI & 6 (IP1.0) & 60 \\
\hline NCTC 5715 & Stm-RIII & 7 (IP2.0) & $60,1 \cdot 3$ \\
\hline NCTC 73 & Stm-RII & 7 (IP2.0) & 60 \\
\hline NCTC 9324 & Stm-RII & 7 (IP2.0) & 60 \\
\hline NCTC 8298 & Stm-RI & 8 (IP2·1) & 60 \\
\hline NCTC 5711 & Stm-RI & $8($ IP2 $2 \cdot 1)$ & 60 \\
\hline NCTC 10413 & Stm-RI & $8($ IP2 $2 \cdot 1)$ & 60 \\
\hline NCTC 74 & Stm-RI & 9 (IP2-2) & 25 \\
\hline NCTC 12023 & Stm-RI & $7(\mathrm{IP} 2 \cdot 3)$ & 60 \\
\hline P199593 (DT 195) & Stm-RI & $9(\mathrm{IP} 1 \cdot 2)$ & 65,4 \\
\hline P100836 (DT 49) & $S t m-\mathrm{RI}$ & 7 (IP2-0) & 60 \\
\hline P226829 (DT 12) & Stm-RI & 12 (IP1-2) & $60,8,3$ \\
\hline P196865 (DT 104) & Stm-RI & $11^{*}$ & 60 \\
\hline P194376 (DT 193) & Stm-RI & $11^{*}$ & $40,4,3$ \\
\hline P188691 (DT 170) & Stm-RI & $10(\mathrm{IP} 1 \cdot 1)$ & 5,2 \\
\hline P194831 (DT 204) & Stm-RI & $6(\mathrm{IP} 2 \cdot 0)$ & $68,4 \cdot 2$ \\
\hline P220187 (DT 108) & Stm-RI & $10(\mathrm{IP} 1 \cdot 1)$ & 70,2 \\
\hline P213623 (DT 208) & Stm-RI & $11($ IP1·1) & 50,6 \\
\hline
\end{tabular}

* Showed characteristics of hybrid profiles.

$6.2,4.5$ and $3.5 \mathrm{kbp}$ ) were conserved across the three profiles. Stm-RII and Stm-RIII shared a $10 \mathrm{kbp}$ band which was absent in Stm-RI and both lacked a $21 \mathrm{kbp}$ band which was present in Stm-RI. The $16 \mathrm{~S}$ rrn profiles of the strains are summarized in Table 2.

\section{Analysis of IS200 insertion sites and assignment of phylogenetically related (IP) groups}

Genomic Southern blots made with PstI, BglII, PvuII and HincII were probed for IS200 as described in Methods. PstI digests, which provided clear resolution of loci with IS200 band sizes ranging from 1.9 to about $24 \mathrm{kbp}$, were used for subsequent analysis. Hybridization data for the genetic/reference strain set are presented in Fig. 2, and for the clinical phage type strain set in Fig. 3. Three common Pst I bands $(4.8,2.4$ and $1.9 \mathrm{kbp})$ were observed in both sets of $S$. typhimurium. The minimum copy number of 6 (Fig. 2, track 3) was exhibited by six strains belonging to the genetic/reference set. The earliest isolated such strain was NCTC 3048, isolated in 1923, and the latest were NCTC 12116 and NCTC 12117, which are mutagenesis-testing strains derived from strain LT2 in 1983 (Maron \& Ames, 1983). The highest copy number of 12 was exhibited by one of the naturally occurring phage type strains, P226829 (DT 12) (Fig. 3, 


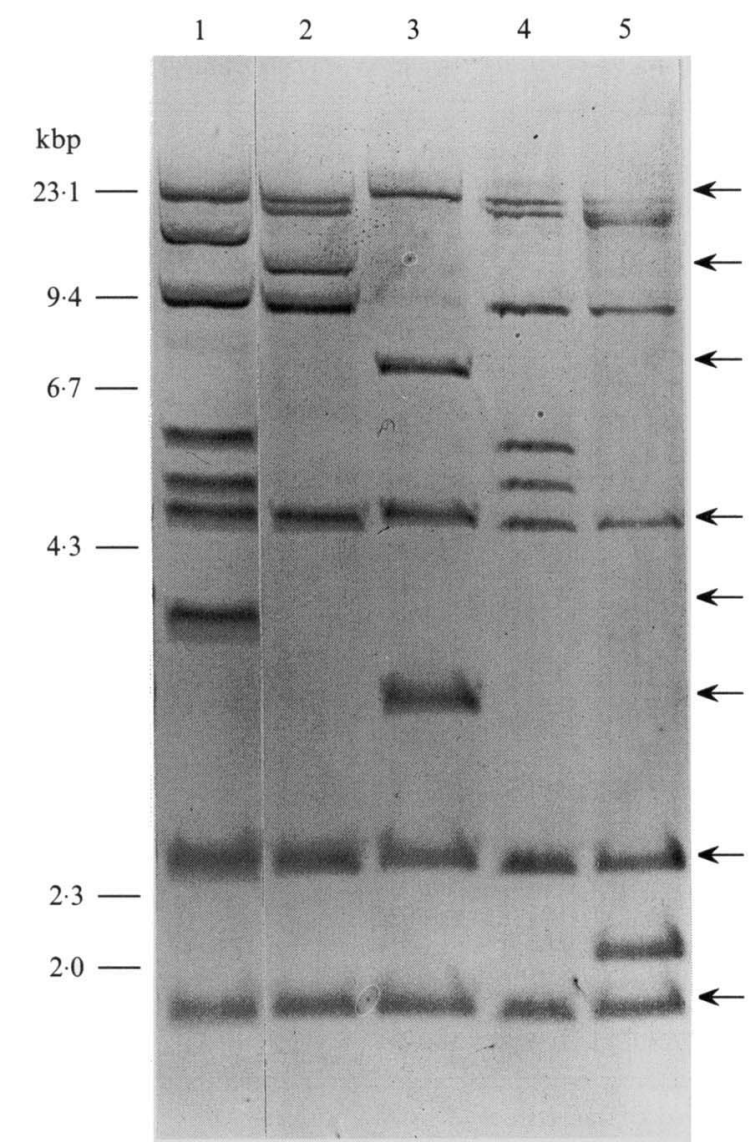

Fig. 2. Conserved IS 200 profiles found among genetic/reference strains. Genomic Southern blot made with Pst $\mathrm{I}$, hybridized with an internal fragment of IS200. Track 1, NCTC 74; track 2, NCTC 73; track 3, NCTC 3048; track 4, NCTC 5711; track 5, NCTC 12023. The IS 200 bands of NCTC 50185 (cf. Fig. 3) are indicated on the right by arrows. Slight differences appearing in mobilities of certain common bands (e.g. the $4.8 \mathrm{kbp}$ band in track 3 ), due to electrophoresis artefacts, were discounted by comparing several gels/blots.

track 2) and in general, IS200 copy numbers were higher in the clinical phage type strain set than in the genetic/reference strain set. The number and complexity of the profiles were reducible to related groups which we chose to term IP (insertion profile) groups. These groups are shown in Table 2 .

Three IS200 profiles were conserved among the genetic/reference strains (Fig. 2, tracks 2, 3, 4) and there were two profiles of which only one example was found (Fig. 2, tracks 1 and 5). The predominant profile was marked by two conserved IS200 bands (PstI : 3.2 and $7 \cdot 1 \mathrm{kbp}$ ) and was termed IP1.0 (copy number $n=6$; Fig. 2 , track 3). It was shared by $8 / 16$ strains in the reference strain set. A laboratory derivative of LT2, NCTC 50185 (SL329 trp) had two extra IS200 sites (Fig. 2, markers at right-hand side; Fig. 3, track 10). It represented a distinct line of descent from the clinical isolates (see below), and was included within IP1.0. A distinct profile shared by NCTC 73, NCTC 9324 and NCTC 5715 ( $n=7$; Fig. 2, track 2) had characteristic insertions in PstI fragments of $9 \cdot 4, \sim 22$ and $\sim 24 \mathrm{kbp}$ was termed IP2.0. Three strains, NCTC 5711, NCTC 8298 and NCTC 10413, shared a related profile ( $n=8$; Fig. 2 , track 4$)$ which had features common to IP2.0 but carried two further insertions, in PstI fragments of 5.4 and $6.4 \mathrm{kbp}$. This was therefore termed IP2.1 to indicate common ancestry. NCTC 74 exhibited a unique profile ( $n=8$; Fig. 2 , track 1$)$ but was again related by possession of the aforementioned two sites of IP2. 1 and is termed IP2 2 . Differences between these profiles were found in a high molecular mass and a $3.9 \mathrm{kbp}$ band found only in IP2.2. The notable feature of NCTC 12023, a US strain, was a $2.1 \mathrm{kbp}$ band not seen in any other strain in either set. Its profile shared two $(9 \cdot 4$ and $24 \mathrm{kbp}$ ) of the three characteristic bands of IP2.0 and was termed IP2.3 (Fig. 2, track 5).

Among the human clinical isolates, two strains exhibited the same profile with a copy number of 10 . They were P220187 (DT 108) and P188691 (DT 170) (Fig. 3, tracks 6 and 9). The fact that these strains had an identical IS200 profile indicates that these phage types are likely to be phenotypic (phage receptor site) variants of otherwise common genotype. All profiles shown in Fig. 3 were consistently reproducible. All the naturally occurring isolates carried the three serotype-specific IS200 bands found in the genetic and reference strains. Differences and groupings among them were readily observable in the two to three bands of highest molecular size. Given the difficulty of comparing individual restriction fragments of this size, these high molecular size bands were scored as a single multistate character (in the interstrain comparisons).

Six naturally occurring isolates shared the $3 \cdot 2$ and $7 \cdot 1 \mathrm{kbp}$ IS 200 bands which had been previously observed in the profile IP1.0, the progenitor six-copy profile of the 'LT2 lineage'. There were two groups of closely related profiles among these strains which had profiles derived from IP1.0. The first group included DT $170 / 108$ $(n=10)$ and DT $208(n=11)$, and was characterized by group-specific bands of 3.5 and $5 \mathrm{kbp}$ (Fig. 3, tracks 9, 6 and 7). The second group of closely related profiles included those of DT $195(n=9)$, and DT $12(n=12)$ (Fig. 3, tracks 8 and 2). This group was characterized by a group-specific band of $15 \mathrm{kbp}$. Since these two divergent groups shared five IS200 bands with IP1.0, they were considered evolutionary derivatives of it and were respectively termed IP $1 \cdot 1$ and IP $1 \cdot 2$. The DT 193 representative showed characteristics of both lines. DT $204(n=6)$ and DT $49(n=7)$ had IS200 profiles (Fig. 3, tracks 5 and 3) which could be closely grouped with that of NCTC 73/NCTC 9324/NCTC 5715; profile 


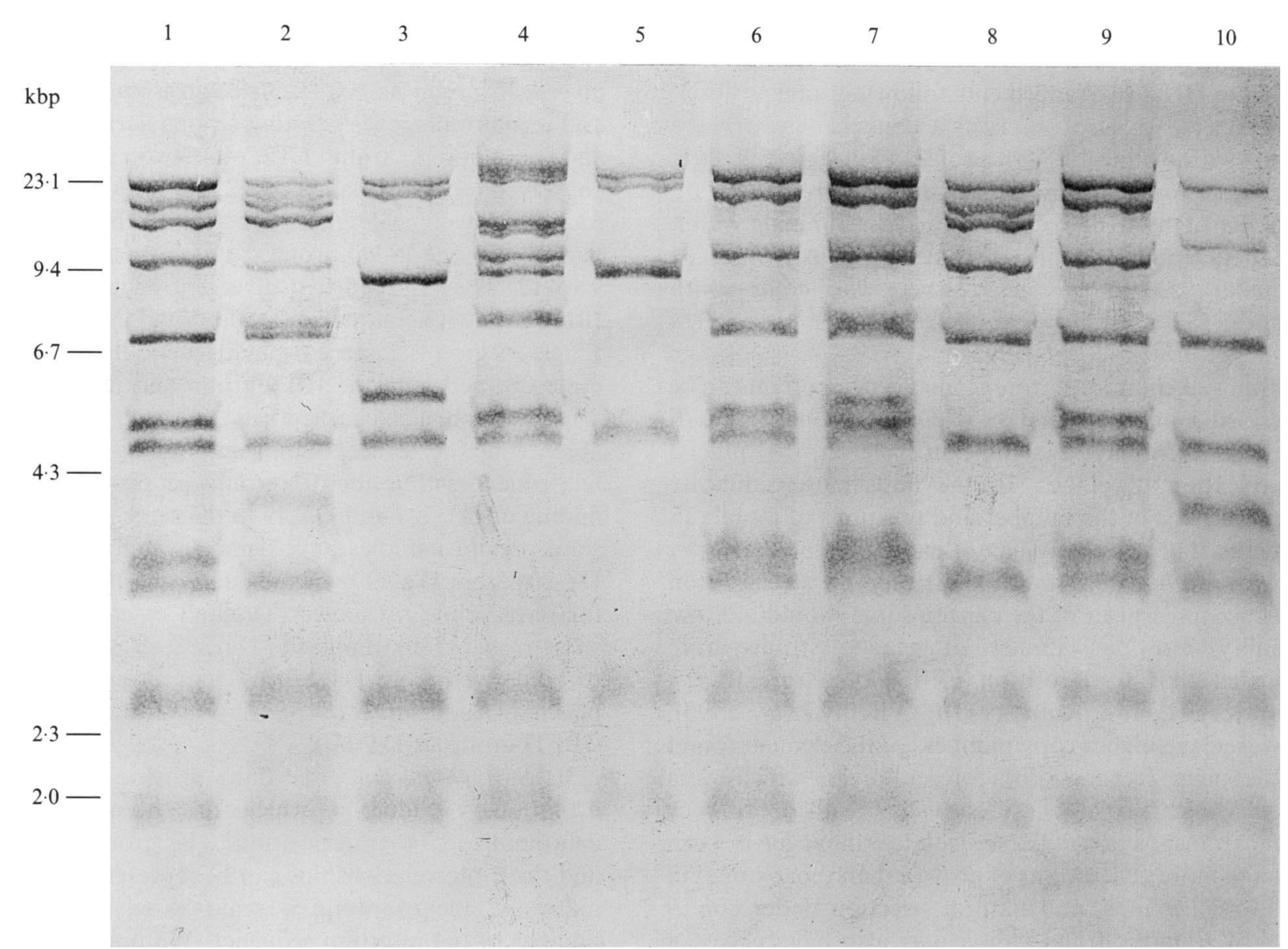

Fig. 3. IS200 profiles of strains representing the clinical phage type strains. Genomic Southern blot (PstI) hybridized with an internal fragment of IS200. Track 1, P194376 (DT 193); track 2, P226829 (DT 12); track 3, P100836 (DT 49); track 4, P196865 (DT 104); track 5, P194831 (DT 204); track 6, P220187 (DT 108); track 7, P213623 (DT 208); track 8, P199593 (DT 195); track 9, P188691 (DT 170); track 10, NCTC 50185. All profiles were unique except for P220187 and P188691, which had an identical profile.

IP2.0 $(n=7)$. The DT 204 profile $(n=6)$ was then considered to be the progenitor profile for this group, whilst the DT 49 profile differed from it only in the position of one band. Phage type DT 104, shared the three serotype-specific bands with other $S$. typhimurium strains (Fig. 3, track 4) and showed characteristics of a hybrid line.

\section{Plasmid analysis}

As shown in Table 2, 15/16 reference strains and 3/9 clinical phage type strains possessed a plasmid of approximately $60 \mathrm{MDa}$, which corresponded to the pSLT mouse virulence-associated plasmid of $S$. typhimurium. In general, naturally occurring strains carried a greater variety of plasmids, particularly small plasmids, some of which encoded antibiotic resistance. NCTC 12116, NCTC 5715 and P226829 (DT 12) also carried small plasmids as well as the $60 \mathrm{MDa}$ plasmid, but these did not encode drug resistance. P194831
(DT 204) carried a $\operatorname{Tn} 10$ insertion in the pSLT-like plasmid. Of the strains lacking the $60 \mathrm{MDa}$ plasmid, NCTC 74 had a single $25 \mathrm{MDa}$ plasmid, P194376 (DT 193) a $40 \mathrm{MDa}$ and two smaller plasmids, whilst P188691 (DT 170) carried only small plasmids of 5 and $2 \mathrm{MDa}$. A $50 \mathrm{MDa}$ plasmid belonging to the FIme incompatibility group was found in P213623 (DT 208). This plasmid is known to determine phage type and its acquisition by strains belonging to DT 170 results in their conversion to DT 208 (Anderson et al., 1977 b). A plasmid of $70 \mathrm{MDa}$ was found in P220187 (DT 108). None of the plasmids had detectable homology with IS200 in Southern blots of analytical plasmid gels.

\section{Discussion}

The majority of the genetic/reference strains and all of the clinical phage type strains shared the same $16 \mathrm{~S} \mathrm{rrn}$ profile as strain LT2. The IS 200 profile provided a high level of discrimination within the predominant $16 \mathrm{~S} \mathrm{rrn}$ 
profile. This is consistent with the fact that differences in the IS 200 profile result both from RFLP at insertion sites and from DNA rearrangements following transposition. Nonetheless, we also observed a converse case, where strains with distinct $16 \mathrm{~S} \mathrm{rrn}$ profiles (Stm-RII and StmRIII) were found within the same IS200 profile (IP2-0). Here, RFLP at a $16 \mathrm{~S}$ rrn locus could discriminate within a particular IS200 profile. We have previously observed a similar case in $S$. dublin, where two clones with identical IS200 profile were marked by distinct $16 \mathrm{~S} \mathrm{rrn}$ profiles (Chowdry et al., 1993).

Strains of common chromosomal genetic origin can be described as clonal (Ørskov \& Ørskov, 1983), and IS elements can play a significant role in the precise identification of clones. If one finds close similarity among strains in the number and positions of mobile IS elements, it provides evidence of recent common ancestry (Sawyer et al., 1987) whilst identity of an insertion sequence fingerprint of the chromosome should indicate clonality. Previous studies of genetic strains have indicated that transposition of IS200 is rare in the laboratory (Lam \& Roth, $1983 a$; O'Reilly et al., 1990). However, the higher copy numbers of the element found in the phage type strain representatives, which were recent clinical isolates, are consistent with continuous IS200 transposition. These isolates may have been through more generations of growth than those stored in culture collections, and natural selection under conditions of zoonotic transmission may also have played a role in determining IS200 copy number. In the clinical set, strains belonging to DT 108 and DT 170 shared the same IS200 profile. DT 108 is distinguished from DT 170 by resistance to typing phage 14 , a phenotype which has therefore probably resulted from mutation in a single gene. Our results suggest that other than this, DT 170 and DT 108 are a single clonal line. The finding of an identical IS200 profile pair in the clinical set gave further confidence in the discriminatory power of IS200 profiling.

There were three conserved IS200 bands in PstI digests which we consider to represent serovar-specific loci, since they were common to all $S$. typhimurium, but were not found in $S$. heidelberg, S. paratyphi B/java, S. enteritidis, S. berta, S. dublin, S. typhi or 27 other serovars examined in our laboratory. Insertions of IS200 in plasmids were not found, indicating that the profiles were chromosomal fingerprints. The serotype of $S$. typhimurium apparently evolved at the time when the number of genomic sites occupied by IS 200 was three. These ancestral sites were among the six genetically mapped as evenly spaced around the LT2 chromosome (Lam \& Roth, 1983b). Two further IS200 bands (PstI) were specific to the major subgroup of $S$. typhimurium, with 'core profile" IP1.0. This PstI profile corresponds to the HincII site analysis described for strain LT2 by Lam \& Roth $(1983 a, b)$. The IP1.0 subgroup included strains as diverse in origin as NCTC 3048, an isolate from 1923, and recent mutagenesis-testing strains derived by Ames and co-workers from LT2. Its two group-specific conserved loci (PstI bands of 3.2 and $7 \cdot 1 \mathrm{kbp}$ ) were also found in $6 / 9$ clinical phage type strains. These six strains had five unique IS200 profiles, and copy numbers from 9 to 12 . They formed two divergent groups IP1.1 and IP1 2 , each with characteristic additional IS200 sites. The IP2 $0 / 2 \cdot 3$ groups represent phylogenetic lines which are quite distinct from the IP1.0 group and its derivatives. The IS200 bands characteristic of each complex are absent in the other. Confirmation of phylogenetic relatedness within the IP groups is provided by the finding of DT 204 and DT 49 in the same (IP2.0) group, since previous studies have demonstrated derivation of DT 204 from DT 49 by acquisition of a plasmid coding for tetracycline resistance (Threlfall et al., 1978; Willshaw et al., 1980). Similarly, DT 208, previously shown to be derived from DT 170 by acquisition of an FIme plasmid (Anderson et al., 1977b) was found in the same (IP1·1) group as DT 170.

In $S$. typhimurium, our data provide a picture of evolutionary radiation which has been marked by continuing IS200 transposition. The groups of strains and their interrelationships can be represented diagrammatically, incorporating a scale based on the copy number of the insertion sequence. We propose that the resulting provisional model (Fig. 4) describes the finestructure phylogenetic history of $S$. typhimurium and confirms that IS200 transposition occurs in nature in this serovar according to a continuous time-branching process. In the model described by Ajioka \& Hartl (1989), the autoregulated rate of transposition, $T(n)$, is a function of the copy number, $n$. Our data for $S$. typhimurium suggest that failure to observe IS200 transposition in the laboratory does not mean that its transposition is absent or very rare in natural biological contexts. However, where IS200 copy numbers are low, $T(n)$ is low and only a limited number of IS200 profiles are found. This is the case for S. enteritidis, where three IS200 profiles based on a copy number of 2 were found (Stanley et al., 1991). It is not the case for $S$. heidelberg, where seven profiles were found based on copy numbers of 4 to 7 (Stanley et al., $1992 c$ ), or for $S$. typhimurium. If IS200 profiling is compared with phage typing, its relative sensitivity is seen also to depend on the range of copy numbers in a given serovar. The 27 phage types of $S$. enteritidis tested fell into one of three IS200 profiles. On the other hand, all except two (DT 108 and DT 170) phage type strains among the clinical isolates in this study had unique IS 200 profiles. This implies that IS200 profiling may be as sensitive as phage typing in $S$. typhimurium: further 


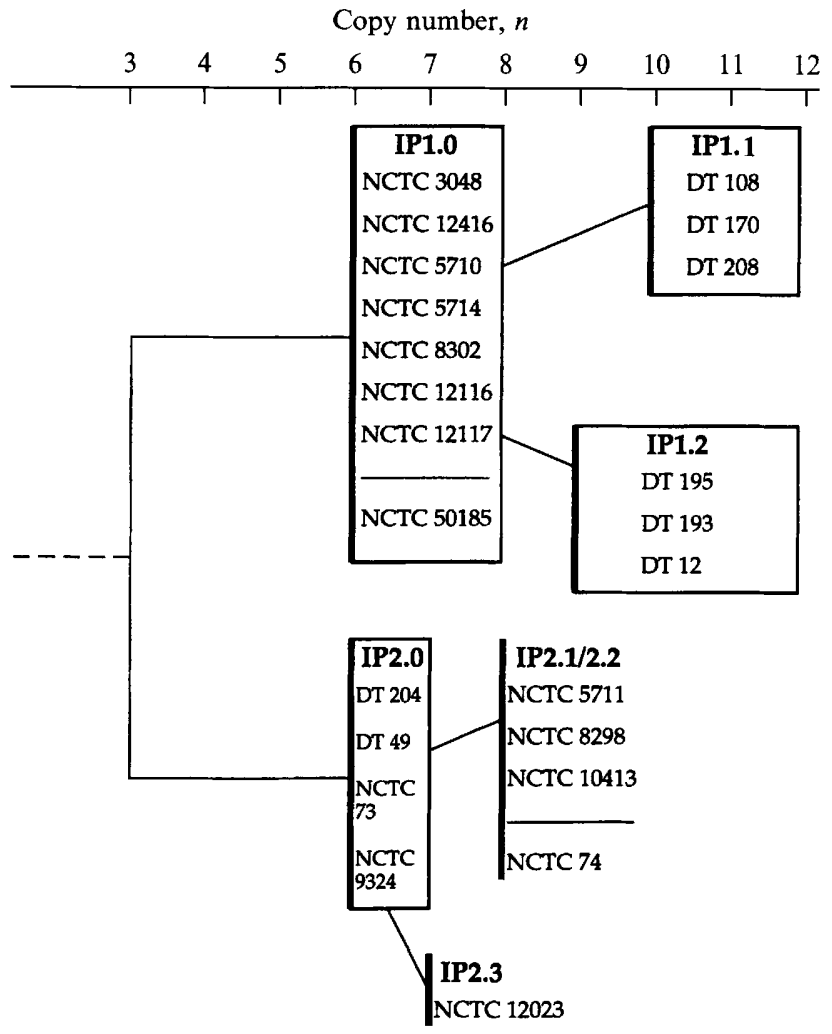

Fig. 4. Provisional phylogenetic history of $S$. typhimurium. The scale at the top of the figure represents the copy number of the element. The profile groups had either a range of copy numbers, shown by the boxes, or a discrete number, shown by a vertical line. Branch points were derived as described in the text. The DT 193 and DT 204 representatives showed characteristics of more than one line.

studies of a wider range of phage types will be needed to elucidate this point. Examination of isolates of a single phage type, DT 204c, of the serovar (N. Baquar and others, unpublished) indicates that it can be subdivided into related IS200 profiles of varying prevalence.

$S$. typhimurium was one of three serovars whose specific antigen profile was shown by multilocus enzyme electrophoresis (MLEE) to be confined to a single cluster of closely related electrophoretic types (ETs), which were considered equivalent to chromosomal genotypes (Beltran et al., 1988). The lines of descent identified as IS200 profile groups in this study presumably occur within that single MLEE cluster, since all share three ancestral insertion sites. Based on their analysis of six different insertion sequences in defined ETs (Selander et al., 1987) of E. coli, Sawyer et al. (1987) showed that insertion sequence loci differentiated strains with considerably more precision than did enzyme electrophoretic mobilities. We have discussed this in relation to our previous findings for IS200 in S. heidelberg (Stanley et $a l ., 1992 c$ ), and similar conclusions may be drawn from the present study. IS200 profiling offers highly defined molecular fingerprinting of the $S$. typhimurium chromo- some, is relatively straightforward technically, and can be displayed in a band-matching database for strain identification. To our knowledge this is the first proposal for a fine-structure phylogenetic history of $S$. typhimurium strains, and the foundations of a molecular epidemiological typing scheme for this serovar are delineated.

We thank Dr Morag Timbury for encouraging development of the molecular fingerprinting of Salmonella, Neville Powell and Clive Jones for technical assistance with certain experiments, and Linda Ward for background information on the $S$. typhimurium phage types and their recent epidemiology.

\section{References}

AJiokA, J. W. \& HARTL, D. L. (1989). Dynamics of transposable elements. In Mobile DNA, pp. 939-958. Edited by D. E. Berg \& M. M. Howe. Washington, DC: American Society for Microbiology. Anderson, E. S., Ward, L. R., DE SAXE, M. J. \& DE SA, J. D. H. (1977a). Bacteriophage-typing designations of Salmonella typhimurium. Journal of Hygiene 78, 297-300.

Anderson, E. S., Threlfall, E. J., Carr, J. M., McConnell, M. M. \& SMITH, H. R. (1977b). Clonal distribution of resistance plasmidcarrying Salmonella typhimurium, mainly in the Middle East. Journal of Hygiene 79, 425 448.

Beltran, P., Musser, J. M., Helmuth, R., Farmer, J. J., Frerichs, W. M., WAChSMUth, I. K., Ferris, K., MCWhorter, A. C., Wells, J. G., Cravioto, A. \& Selander, R. K. (1988). Towards a population genetic analysis of Salmonella: genetic diversity and relationships among strains of serotypes $S$. choleraesuis, $S$. derby, $S$. dublin, S. enteritidis, $S$. heidelberg, $S$. infantis, $S$. newport and S. typhimurium. Proceedings of the National Academy of Sciences of the United States of America 85, 7753-7757.

Brosius, J., Palmer, M. L., Kennedy, P. J. \& Noller, H. F. (1978). Complete nucleotide sequence of $16 \mathrm{~S}$ ribosomal RNA gene from Escherichia coli. Proceedings of the National Academy of Sciences of the United States of America 75, 4801-4805.

Callow, B. R. (1959). A new phage typing scheme for Salmonella typhimurium. Journal of Hygiene 57, 346-359.

Chowdry, N., Threlfall, E. J., Rowe, B. \& Stanley, J. (1993) Genotype analysis of faecal and blood isolates of Salmonella dublin from humans in England and Wales. Epidemiology and Infection 110, 217-225.

Demerec, M., Bloomstrand, I. \& Demerec, Z. E. (1955). Evidence of complex loci in Salmonella. Proceedings of the National Academy of Sciences of the United States of America 41, 359-364.

GALAS, D. J. \& ChANDLER, M. (1989). Bacterial insertion sequences. In Mobile DNA, pp. 109-162. Edited by D. E. Berg \& M. M. Howe. Washington, DC: American Society for Microbiology.

Gibert, I., BARbe, J. \& Casadesus, J. (1990). Distribution of insertion sequence IS200 in Salmonella and Shigella. Journal of General Microbiology 136, 2555-2560.

Gibert, I., Carroll, I., Hillyard, D. R., Barbe, J. \& Casadesus, J. (1991). IS200 is not a member of the IS600 family of insertion sequences. Nucleic Acids Research 19, 1343.

InNis, M. A., Gelfand, D. H., Sninsky, J. J. \& White, T. J. (1990). PCR Protocols. A Guide to Methods and Applications. New York: Academic Press.

Kado, C. I. \& LIU, S.-T. (1981). Rapid procedure for detection of large and small plasmids. Journal of Bacteriology 145, 1365-1375.

LAM, S. \& RoTH, J. R. (1983a). IS200: a Salmonella-specific insertion sequence. Cell 34, 951-960.

LAM, S. \& RoTH, J. R. (1983 b). Genetic mapping of IS 200 copies in Salmonella typhimurium strain LT2. Genetics 105, 801-811.

LAM, S. \& RoTH, J. R. (1986). Structural and functional studies of insertion element IS200. Journal of Molecular Biology 187, 157-167.

LE MINOR, L. (1988). Typing of Salmonella species. European Journal of Clinical Microbiology and Infectious Disease 7, 214-218. 
LilleENGen, K. (1948). Typing Salmonella typhimurium by means of bacteriophage. Acta Pathologica et Microbiologica Scandinavica, Supplement 77, 11-125.

MARON, D. M. \& AMES, B. N. (1983). Revised methods for the Salmonella mutagenicity test. Mutagenetic Research 113, 173-215.

Norel, F., Coynault, C., Miras, I., Hermant, D. \& Popoff, M. Y. (1989). Cloning and expression of plasmid DNA sequences involved in Salmonella serotype typhimurium virulence. Molecular Microbiology 3, 733-743.

O'Reilly, C., Black, G. W. LafFey, R. \& McConnell, D. J. (1990). Molecular analysis of an IS200 insertion in the gpt gene of Salmonella typhimurium. Journal of Bacteriology 172, 6599-6601.

ØRSKOV, F. \& ØRSKOV, I. (1983). Summary of a workshop on the clone concept in the epidemiology, taxonomy, and evolution of the Enterobacteriaceae and other bacteria. Journal of Infectious Diseases 148, 346-357.

Sambrook, J., Fritsch, E. F. \& Maniatis, T. (1989). Molecular Cloning. A Laboratory Manual, 2nd edn. Cold Spring Harbor, NY: Cold Spring Harbor Laboratory.

SANDerson, K. E. \& Stocker, B. A. D. (1987). Salmonella typhimurium strains used in genetic analysis. In Escherichia coli and Salmonella typhimurium. Cellular and Molecular Biology, vol. 2, pp. 1220-1224. Edited by F. C. Neidhardt, J. L. Ingraham, K. B. Low, B. Magasanik, M. Schaechter \& H. E. Umbarger. Washington, DC: American Society for Microbiology.

Sawyer, S. A., Dykhuizen, D. E., Dubose, R. F., Green, L., Mutangadura-Mhlanga, T., WolczyK, D. F. \& Hartl, D. L. (1987). Distribution and abundance of insertion sequences among natural isolates of Escherichia coli. Genetics 115, 51-63.

Selander, R. K., Caugant, D. A. \& Whittam, T. S. (1987). Genetic structure and variation in natural populations of Escherichia coli. In Escherichia coli and Salmonella typhimurium. Cellular and Molecular Biology, vol. 2, pp. 1625-1648. Edited by F. C. Neidhardt, J. L. Ingraham, K. B. Low, B. Magasanik, M. Schaechter \& H. E. Umbarger. Washington, DC: American Society for Microbiology.
Stanley, J., Jones, C. S. \& Threlfall, E. J. (1991). Evolutionary lines among Salmonella enteritidis phage types are identified by insertion sequence IS200 distribution. FEMS Microbiology Letters 82, 83-90.

Stanley, J., Goldsworthy, M. \& Threlfall, E. J. (1992a). Molecular phylogenetic typing of pandemic isolates of Salmonella enteritidis. FEMS Microbiology Letters 90, 153-160.

Stanley, J., Chowdry, N., Powell, N. \& Threlfall, E. J. (1992b) Chromosomal genotypes (evolutionary lines) of Salmonella berta. FEMS Microbiology Letters 95, 247-252.

Stanley, J., Burnens, A., Powell, N., Chowdry, N. \& Jones, C. $(1992 c)$. The insertion sequence IS200 fingerprints chromosomal genotypes and epidemiological relationships in Salmonella heidelberg. Journal of General Microbiology 138, 2329-2336.

Threlfall, E. J. \& Frost, J. A. (1990). The identification and fingerprinting of Salmonella: laboratory aspects and epidemiological applications. Journal of Applied Bacteriology 68, 5-16.

Threlfall, E. J., WarD, L. R. \& Rowe, B. (1978). Epidemic spread of a chloramphenicol-resistant strain of Salmonella typhimurium phage type 204 in bovine animals in Britain. Veterinary Research 103, 438-440.

Threlfall, E. J., Frost, J. A., Ward, L. R. \& Rowe, B. (1990). Plasmid profile typing can be used to subdivide phage-type 49 of Salmonella typhimurium in outbreak investigations. Epidemiology and Infection 104, 243-251.

Threlfall, E. J., Rowe, B. \& WARD, L. R. (1992). Recent changes in the occurrence of antibiotic resistance in Salmonella isolated in England and Wales. PHLS Microbiology Digest 9, 69-71.

Willshaw, G. A., Threlfall, E. J., Ward, L. R., Ashley, A. S. \& Rowe, B. (1980). Plasmid studies of drug-resistant epidemic strains of Salmonella typhimurium belonging to phage types 204 and 193 . Journal of Antimicrobial Chemotherapy 6, 763-773.

Wilson, K. (1987). Preparation of genomic DNA from bacteria. Current Protocols in Molecular Biology, Unit 2.4.1. New York: Wiley.

ZINDER, N. D. \& LEDERBERG, J. (1952). Genetic exchange in Salmonella. Journal of Bacteriology 64, 679-699. 